\title{
Genetic implications of double primary cancers of the colorectum and endometrium
}

Tuya Pal, Tamar Flanders, Margot Mitchell-Lehman, Andrée MacMillan, Jean-Sebastien Brunet, Steven A Narod, William D Foulkes

\begin{abstract}
Hereditary non-polyposis colorectal cancer (HNPCC) is an autosomal dominant condition predisposing to cancers of the colorectum and endometrium. Endometrial cancer is the most commonly occurring extracolonic cancer in HNPCC. Estimates of the cumulative incidence of endometrial cancer in women with mutations in the HNPCC genes range from $22-43 \%$.
\end{abstract}

In order to determine how frequently double primary cancers of the colorectum and endometrium are the result of a hereditary factor, we conducted a registry based study in Ontario and Quebec, Canada. We obtained pedigrees on 80 women diagnosed with double primary cancers of the colorectum and endometrium at less than 70 years of age. Family histories of cancer were obtained for all first degree relatives of these women and cancer rates were compared with age standardised provincial incidence rates in order to estimate the relative risks. There was a total of 82 cancers observed in relatives below the age of 55, compared with 31.2 expected, giving a relative risk of 2.6 (95\% confidence interval (CI) 2.1-3.3). The relative risk for colorectal cancer below 55 was 16.1 (95\% CI 11.6-21.8). This risk decreased with increasing age of onset of cancers in probands. For probands with both colorectal and endometrial cancer diagnosed under the age of 55 , the relative risk of colorectal cancer in relatives below the age of 55 was 30.5 (95\% CI 18.8-46.6). Similar patterns were observed for endometrial and pancreatic cancer. There were non-significant increases in rates of cancer of the oesophagus, stomach, small intestine, and bladder. There was no increased risk of breast cancer. The risk of lung cancer was decreased, especially in older relatives.

Our findings indicate the presence of a significant genetic component of cancer in women with double primary cancers of the colorectum and endometrium. $(\mathcal{O}$ Med Genet 1998;35:978-984)

Keywords: colorectal cancer; endometrial cancer; hereditary non-polyposis colorectal cancer

Correspondence to:

Dr Narod, 790 Bay Street,

7th Floor, Toronto, Ontario, Canada M5G 1N8.

Received 2 December 1997 Revised version accepted for publication 23 April 1998
There are several dominantly inherited cancer syndromes. These are characterised by several features, including multiple primary cancers in a person, cancer occurring at an earlier age than in the general population, and cancer affecting multiple family members. Recently, the underlying genetic defect for many cancer syndromes has been discovered.

Hereditary non-polyposis colorectal cancer (HNPCC) is an autosomal dominant inherited cancer susceptibility syndrome which is believed to account for up to $6 \%$ of all colorectal cancer cases. ${ }^{1}$ Endometrial cancer is the most commonly occurring extracolonic cancer in HNPCC and estimates of the cumulative incidence of this cancer in women with mutations in the HNPCC genes range from $22-43 \% .^{2-4}$ In addition to the increased risk of colorectal cancer, there is an increased incidence of adenocarcinoma of the endometrium and, to a lesser degree, cancer of the stomach, urinary tract, and other sites. ${ }^{2-8}$ Endometrial cancers in HNPCC families occur at an earlier age than those seen in the general population. ${ }^{9}$

If multiple primary cancers are primarily the result of hereditary factors, we would expect to see an increased cancer risk in relatives, and the increase should be greater than that associated with each site alone. To test this hypothesis, we identified women in Ontario and Quebec with both colorectal and endometrial cancer. A detailed family history of cancer in all first degree relatives was obtained from each subject.

\section{Materials and methods}

ASCERTAINMENT OF PROBANDS

We used two population based registries and four hospital based registries. The Ontario Cancer Registry (OCR) and the tumour registry at the Princess Margaret Hospital (PMH) contain information on patients who are diagnosed with all types of cancer. All entries for living cases for the years 1971-1996 from the OCR and for all living and dead cases from the PMH with the diagnosis of colorectal and endometrial cancer by the age of 70 years were reviewed. There was a total of 107 cases identified in Ontario, of which 26 cases overlapped between the provincial and hospital registries. Similarly, the Quebec Cancer Registry and the tumour registries at the Royal Victoria Hospital, Montreal General Hospital, and the Sir Mortimer B Davis-Jewish General Hospital contain information on people diagnosed with cancer; all entries of living and dead subjects with the diagnosis of colorectal and endometrial cancer by the age of 70 years were reviewed at these institutions. There was a total of 44 cases identified in Quebec, of which seven cases were identified in both the provincial and hospital registries. 
Table 1 Changes of cancer diagnoses

\begin{tabular}{ll}
\hline Reported cancer & Verified cancer \\
\hline Endometrial cancer & Endometrial cancer, bladder cancer \\
Stomach cancer & Stomach cancer, endometrial cancer \\
Liver cancer & Pancreatic cancer \\
Stomach cancer & Pancreatic cancer \\
Pancreatic cancer & $\begin{array}{l}\text { Pancreatic cancer, endometrial } \\
\text { cancer }\end{array}$ \\
Colon cancer & Endometrial cancer \\
Liver cancer & Colon cancer \\
Colon cancer & Colon cancer, endometrial cancer \\
Stomach cancer & Small intestinal cancer \\
Endometrial cancer & Ovarian cancer \\
Primary site unknown & Cancer of the colon, endometrium, \\
& kidney, and bladder \\
\hline
\end{tabular}

Of the 107 pathology confirmed cases identified in Ontario and 44 pathology confirmed cases identified in Quebec, 87 of the subjects were living and 64 had died. It was possible to contact the proband in 70 of the 87 living cases $(80.4 \%)$ and the next of kin in 28 of the 64 dead cases $(43.8 \%)$. In 53 cases, no contact could be made. In 16 cases, the proband or next of kin declined to participate. In two cases, the next of kin agreed to participate in the study but was unable to provide any family history information. Of the 98 cases contacted, pedigrees were obtained for 80 subjects $(81.6 \%$ participation rate). Of the 80 subjects, 35 had colorectal cancer followed by endometrial cancer, 38 had endometrial cancer followed by colorectal cancer, and seven had both cancers synchronously.

The interview was conducted with the proband in 62 cases and with a family member in 18 cases. The interviews were conducted either in person or by telephone. The family history included current age or age of death,

Table 2 Summary of probands, first degree relatives, and person years in the different subgroups of probands

\begin{tabular}{lllll}
\hline & $\begin{array}{l}\text { No of } \\
\text { probands }\end{array}$ & $\begin{array}{l}\text { No of } \\
\text { relatives }\end{array}$ & $\begin{array}{l}\text { No of female } \\
\text { relatives }\end{array}$ & $\begin{array}{l}\text { No of person } \\
\text { years }\end{array}$ \\
\hline All probands & 80 & 640 & 324 & 35758 \\
Probands with colorectal cancer $<55$ & 32 & 241 & 113 & 13110 \\
Probands with endometrial cancer $<55$ & 36 & 330 & 164 & 17591 \\
Probands with both cancers $<55$ & 21 & 177 & 85 & 9320 \\
Probands with both cancers $>55$ & 33 & 246 & 133 & 13570 \\
\hline
\end{tabular}

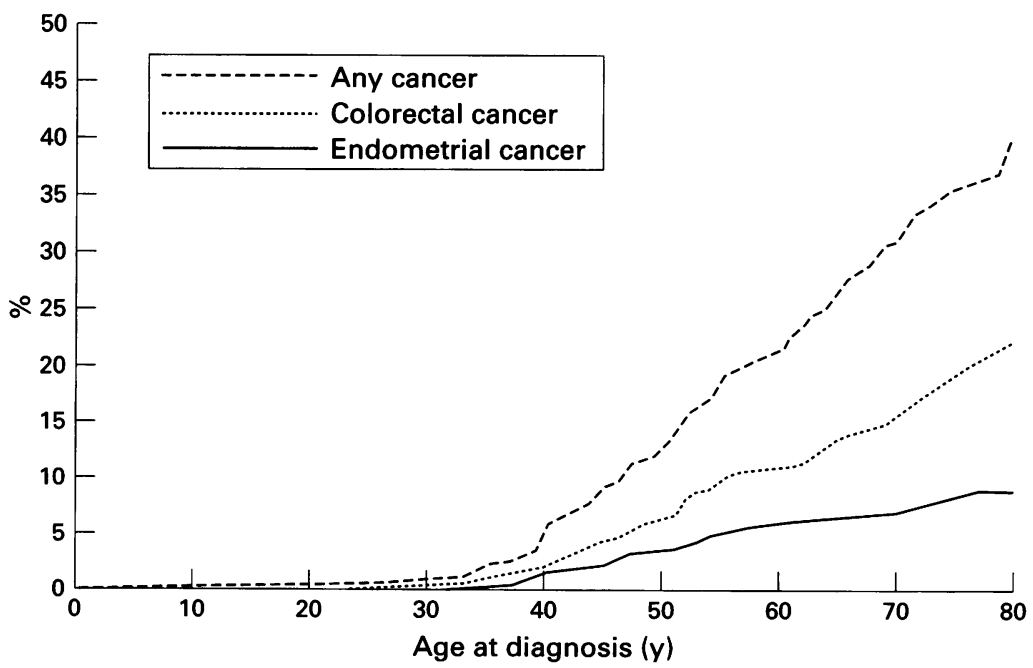

Figure 1 Cumulative incidence of cancer in relatives of patients with double primary cancers of the colorectum and endometrium. The cumulative incidence for any cancer and colorectal cancer is based on 640 relatives (males and females), while the cumulative incidence for endometrial cancer is based on 327 female relatives. age of diagnosis of cancer, and site (and where possible, histological type) of cancer in all first degree relatives of the proband. Attempts were made to verify the diagnosis of cancer in the first degree relatives of the Ontario probands but not in Quebec. In Ontario, documentation was obtained in 49 of the 92 reported cases of cancer $(53 \%)$. Of these 49 cases, 38 were reported accurately $(80 \%)$; in the remaining 11 cases, there were five errors in reporting and six omissions of additional cancer diagnoses (table 1). When pathological confirmation was not available, the cancer diagnosis was taken as that reported by the relative. However, the diagnosis of cancer reported in first degree relatives is very likely to be accurate. ${ }^{1011}$

\section{STATISTICAL ANALYSIS}

The observed number of cases $(O)$ in the first degree relatives was determined by review of family pedigrees. The expected number of cases for each cancer was calculated from the product of the person years and the combined Ontario and Quebec provincial cancer rate for each age range. People were considered to be at risk of cancer from birth until death or age in 1996. The expected number of cases (E) was calculated for each of the age ranges selected. The relative risk of cancer in first degree relatives of probands was estimated by comparing observed to expected figures. The confidence intervals (CI) were calculated assuming a Poisson distribution, $\mathrm{CI}=\mathrm{O}_{\mathrm{L}} / \mathrm{E}-\mathrm{O}_{\mathrm{U}} / \mathrm{E}$, where $\mathrm{O}_{\mathrm{L}}$ and $\mathrm{O}_{\mathrm{U}}$ are the lower and upper bounds respectively. ${ }^{12}$

\section{Results}

There were 80 probands with double primary cancers of the colorectum and endometrium. These women had 640 first degree relatives (an average of 8.0 relatives per proband ) who contributed 35758 person years of follow up (table 2). A total of 140 cancers were reported among the 640 relatives $(22 \%)$. The risk of cancer of any type in relatives to age 80 was $40.2 \%$ (fig 1). Although the relative risks for colorectal and endometrial cancer were similar, the cumulative incidence of colorectal cancer was double that of endometrial cancer. The cumulative incidences for colorectal cancer in first degree relatives to ages 55 and 80 were $9.9 \%$ and $22.4 \%$, respectively. For endometrial cancer, the cumulative incidence in first degree female relatives was $4.8 \%$ to age 55 and $9.0 \%$ to age 80 .

Cancer risk estimates for the first degree relatives are presented in table 3A. The relative risk for any cancer was substantially increased, especially for cancers below the age of 55 . The risks for colorectal and endometrial cancer in relatives was markedly increased. The risk in relatives for these cancers after the age of 55 was increased to a lesser extent. Although there were moderate increases in risk for cancers of the oesophagus, stomach, small intestine, pancreas, bladder, and ovary (especially in relatives under the age of 55), only pancreatic and ovarian cancer were significantly increased at the $5 \%$ level. The relative risk for breast cancer was not increased (relative risk 0.9 ) and the risk for 
Table $3 A$ Relative risk of cancer in first degree relatives associated with a double primary cancer of the colorectum and endometrium in the proband

\begin{tabular}{|c|c|c|c|c|c|}
\hline Cancer site & Age & Observed & Expected & $R R$ & $95 \% C I$ \\
\hline \multirow[t]{3}{*}{ Any cancer } & $<55$ & 82 & 31.2 & 2.6 & $2.1-3.3$ \\
\hline & $\geqslant 55$ & 58 & 71.5 & 0.8 & $0.6-1.0$ \\
\hline & Any age & 140 & 102.6 & 1.4 & $1.1-1.6$ \\
\hline \multirow[t]{3}{*}{ Colorectum } & $<55$ & 41 & 2.5 & 16.1 & $11.6-21.8$ \\
\hline & $\geqslant 55$ & 29 & 12.0 & 2.4 & $1.6-3.5$ \\
\hline & Any age & 70 & 14.6 & 4.8 & $3.7-6.1$ \\
\hline \multirow[t]{3}{*}{ Endometrium } & $<55$ & 11 & 0.7 & 15.4 & $7.7-27.6$ \\
\hline & $\geqslant 55$ & 5 & 2.0 & 2.5 & $0.8-5.8$ \\
\hline & Any age & 16 & 2.7 & 5.9 & $3.4-9.6$ \\
\hline \multirow{3}{*}{ Oesophageal } & $<55$ & 1 & 0.1 & 7.4 & $0.1-40.9$ \\
\hline & $\geqslant 55$ & 3 & 0.9 & 3.3 & $0.7-9.8$ \\
\hline & Any age & 4 & 1.0 & 3.9 & $1.0-9.9$ \\
\hline \multirow{3}{*}{ Stomach } & $<55$ & 1 & 0.5 & 2.0 & $0-10.9$ \\
\hline & $\geqslant 55$ & 3 & 2.4 & 1.2 & $0.3-3.6$ \\
\hline & Any age & 4 & 2.9 & 1.4 & $0.4-3.5$ \\
\hline \multirow{3}{*}{ Small intestine } & $<55$ & 1 & 0.1 & 15.3 & $0.2-85.2$ \\
\hline & $\geqslant 55$ & 1 & 0.2 & 4.2 & $0.1-23.4$ \\
\hline & Any age & 2 & 0.3 & 6.6 & $0.7-23.9$ \\
\hline \multirow{3}{*}{ Pancreas } & $<55$ & 4 & 0.4 & 11.3 & $3.0-28.9$ \\
\hline & $\geqslant 55$ & 4 & 2.1 & 1.9 & $0.5-4.8$ \\
\hline & Any age & 8 & 2.5 & 3.2 & $1.4-6.3$ \\
\hline \multirow{3}{*}{ Bladder } & $<55$ & 2 & 0.7 & 3.0 & $0.3-10.8$ \\
\hline & $\geqslant 55$ & 3 & 3.7 & 0.8 & $0.2-2.4$ \\
\hline & Any age & 5 & 4.4 & 1.1 & $0.4-2.7$ \\
\hline \multirow{3}{*}{ Ovary } & $<55$ & 4 & 1.0 & 4.2 & $1.1-10.7$ \\
\hline & $\geqslant 55$ & 1 & 1.3 & 0.8 & $0-4.2$ \\
\hline & Any age & 5 & 2.3 & 2.2 & $0.7-5.1$ \\
\hline \multirow[t]{3}{*}{ Breast } & $<55$ & 6 & 6.8 & 0.9 & $0.3-1.9$ \\
\hline & $\geqslant 55$ & 7 & 8.4 & 0.8 & $0.3-1.7$ \\
\hline & Any age & 13 & 15.2 & 0.9 & $0.5-1.5$ \\
\hline \multirow[t]{3}{*}{ Lung } & $<55$ & 2 & 3.0 & 0.7 & $0.1-2.4$ \\
\hline & $\geqslant 55$ & 4 & 14.4 & 0.3 & $0.1-0.7$ \\
\hline & Any age & 6 & 17.5 & 0.3 & $0.1-0.7$ \\
\hline
\end{tabular}

lung cancer was slightly decreased (relative risk $0.3,95 \%$ CI $0.1-0.7)$. When the data were analysed with subsets of probands (table 3B) with younger ages of onset of the cancers, the trends seen for colorectal, endometrial, and pancreatic cancer were similar, but the increases in relative risks were magnified.

Risks were similar for the dead and living cases. The relative risk in first degree relatives for cancer under the age of 55 for dead cases was 3.4 (95\% CI 2.3-4.9) and for living cases was 2.3 (95\% CI 1.7-3.0). For cancers over the age of 55, the ratios were 1.2 (95\% CI 0.7-1.9) and 0.7 (95\% CI 0.5-1.0) for dead and living cases respectively.

Before determining the genetic defect underlying HNPCC, the diagnosis of hereditary colon cancer was based on clinical grounds (Amsterdam criteria) which consisted of: (1) histologically verified colorectal cancer in three or more relatives, one of whom is a first degree relative of the other two, (2) colorectal cancer involving at least two generations, (3) one or more colorectal cancer cases diagnosed before the age of 50, and (4) familial adenomatous polyposis (FAP) excluded. Although these criteria are useful in identifying highly penetrant families, they are of less use in determining the full spectrum of disease. In our study, there were 14 of 80 families (18\%) that satisfied the Amsterdam criteria. Fig 2A shows a family identified through the study that clearly meets these criteria. There are multiply affected relatives with colorectal cancer at young ages spanning three generations. However, a number of families were identified that did not satisfy the Amsterdam criteria, but where a genetic component was nevertheless suspected. Fig 2B shows a family with a very strong history of extracolonic cancers. Fig 2C shows a small pedigree with a strong family history of cancer over two generations. These examples reinforce the difficulty of diagnosing HNPCC in small families and the importance of considering extracolonic cancers.

We classified all families into three categories based on family history as shown in table 4 : familial, possibly familial, and non-familial. Our criteria for familial colon cancer differs from the Amsterdam criteria in that both extracolonic cancers and the age of onset of colorectal and endometrial cancer are taken into account. According to the criteria, 21 families were "familial", 17 families were "possibly familial", and 41 families were "nonfamilial".

\section{Discussion}

The occurrence of two primary tumours in one person suggests that a genetic susceptibility component may be present. ${ }^{13}$ Although the association between colorectal and endometrial cancer is known in HNPCC, no studies have specifically attempted to document family histories of women with both colorectal and endometrial cancer. It is possible that both cancers in the same woman could be the result of chance, and hence would not be expected to be associated with a family history of cancer. However, our study has shown that relatives of a woman with a double primary cancer of the colorectum and endometrium are at greatly increased risks for developing colorectal, endometrial, and pancreatic cancers.

The risks for colorectal cancer and endometrial cancer associated with a family history of double primary cancers at these sites are

Table $3 B$ Relative risk of cancer in first degree relatives associated with double primary cancer of the colorectum and endometrium in different subgroups of probands

\begin{tabular}{|c|c|c|c|c|c|c|c|c|c|}
\hline \multirow[b]{2}{*}{ Cancer site } & \multirow[b]{2}{*}{ Age } & \multicolumn{4}{|c|}{ Probands with colorectal cancer $<55$} & \multicolumn{4}{|c|}{ Probands with endometrial cancer $<55$} \\
\hline & & Observed & Expected & $R R$ & $95 \% C I$ & Observed & Expected & $R R$ & $95 \% C I$ \\
\hline \multirow[t]{3}{*}{ Any cancer } & $<55$ & 50 & 11.4 & 4.4 & $3.2-5.8$ & 64 & 15.7 & 4.1 & $3.1-5.2$ \\
\hline & $>55$ & 27 & 23.3 & 1.2 & $0.8-1.7$ & 31 & 26.8 & 1.2 & $0.8-1.6$ \\
\hline & Any & 77 & 34.7 & 2.2 & $1.8-2.8$ & 95 & 42.5 & 2.2 & $1.8-2.7$ \\
\hline \multirow[t]{3}{*}{ Colorectum } & $<55$ & 24 & 0.9 & 25.3 & $16.2-37.6$ & 34 & 1.3 & 26.3 & $18.2-36.8$ \\
\hline & $>55$ & 13 & 4 & 3.3 & $1.7-5.6$ & 18 & 4.7 & 3.8 & $2.3-6.1$ \\
\hline & Any & 37 & 4.9 & 7.5 & $5.3-10.4$ & 52 & 6.0 & 8.7 & $6.5-11.4$ \\
\hline \multirow[t]{3}{*}{ Endometrium } & $<55$ & 6 & 0.2 & 24.1 & $8.8-52.6$ & 11 & 0.4 & 31.4 & $15.6-56.1$ \\
\hline & $>55$ & 3 & 0.6 & 4.8 & $1.0-13.4$ & 2 & 0.8 & 2.6 & $0.3-9.3$ \\
\hline & Any & 9 & 0.9 & 10.3 & $4.7-19.5$ & 13 & 1.1 & 11.6 & $6.1-19.8$ \\
\hline \multirow[t]{3}{*}{ Pancreas } & $<55$ & 4 & 0.1 & 30 & $8.1-76.9$ & 4 & 0.2 & 22.2 & $6.0-56.9$ \\
\hline & $>55$ & 2 & 0.7 & 2.8 & $0.3-10.1$ & 3 & 0.9 & 3.5 & $0.7-10.2$ \\
\hline & Any & 6 & 0.8 & 7.1 & $2.6-15.4$ & 7 & 1.0 & 6.7 & $2.7-13.9$ \\
\hline
\end{tabular}




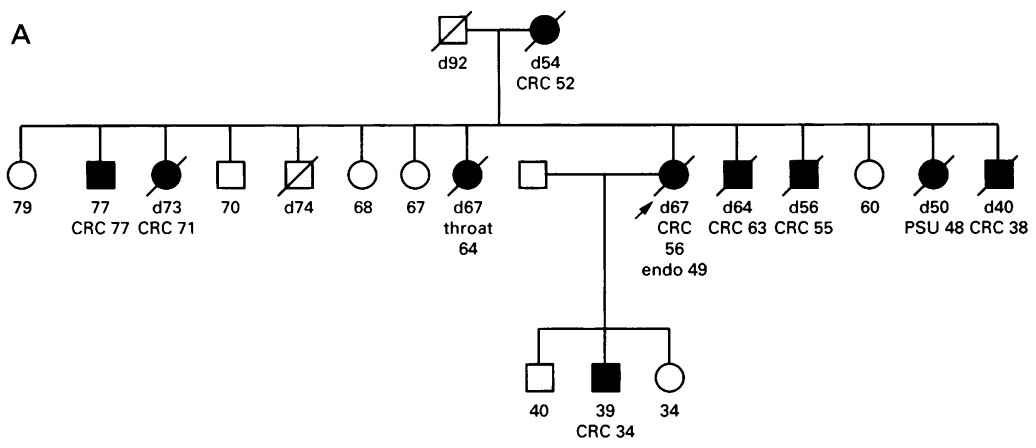

CRC - colorectal cancer endo - endometrial cancer PSU - primary site of cancer unknown

B

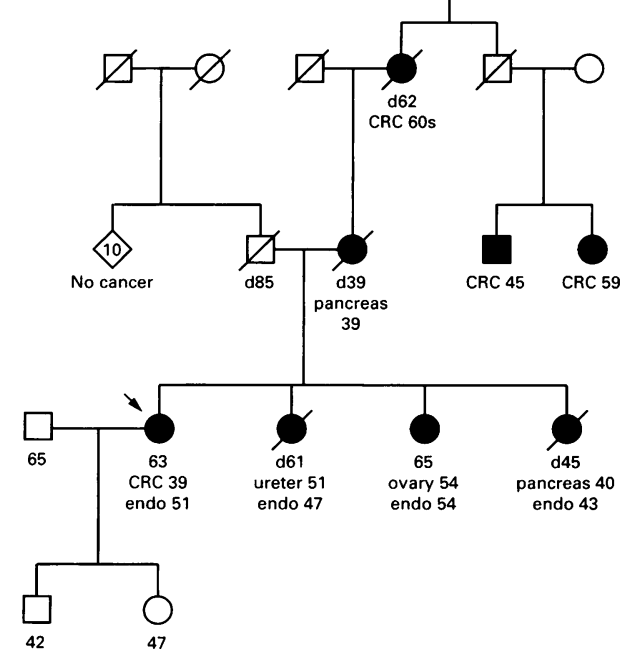

C

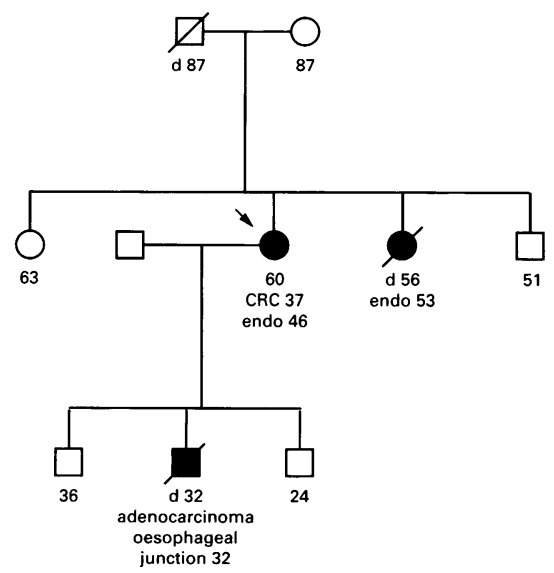

Figure 2 Pedigrees of selected families identified in the study.

Table $3 B$ continued

\begin{tabular}{|c|c|c|c|c|c|c|c|}
\hline \multicolumn{4}{|c|}{ Probands with both cancers $<55$} & \multicolumn{4}{|c|}{ Probands with both cancer $>55$} \\
\hline Observed & Expected & $R R$ & $95 \% C I$ & Observed & Expected & $R R$ & $95 \% C I$ \\
\hline 44 & 8.3 & 5.3 & $3.8-7.1$ & 12 & 12.4 & 1.0 & $0.5-1.7$ \\
\hline 16 & 13.1 & 1.2 & $0.7-2.0$ & 16 & 34.5 & 0.5 & $0.3-0.8$ \\
\hline 60 & 21.4 & 2.8 & $2.1-3.6$ & 28 & 46.9 & 0.6 & $0.4-0.9$ \\
\hline 21 & 0.7 & 30.5 & $18.8-46.6$ & 4 & 1.0 & 4.0 & $1.1-10.3$ \\
\hline 8 & 2.3 & 3.5 & $1.5-6.8$ & 6 & 5.7 & 1.1 & $0.4-2.3$ \\
\hline 29 & 3 & 9.7 & $6.5-13.9$ & 10 & 6.7 & 1.5 & $0.7-2.8$ \\
\hline 6 & 0.2 & 32.5 & $11.9-70.7$ & 0 & 0.3 & - & - \\
\hline 2 & 0.4 & 4.9 & $0.5-17.6$ & 2 & 1.0 & 2.0 & $0.2-7.1$ \\
\hline 8 & 0.6 & 13.5 & $5.8-26.5$ & 2 & 1.3 & 1.5 & $0.2-5.5$ \\
\hline 4 & 0.1 & 41.4 & $11.1-105.9$ & 0 & 0.1 & - & - \\
\hline 2 & 0.4 & 4.8 & $0.5-17.1$ & 1 & 1.0 & 1.0 & $0-5.6$ \\
\hline 6 & 0.5 & 11.6 & $4.2-25.2$ & 1 & 1.1 & 0.9 & $0-4.9$ \\
\hline
\end{tabular}

greater than the risks associated with a family history of cancers at a single site. From two cohort studies, 119116 US health workers provided details of a family history of cancer. ${ }^{14}$ Using a person years approach, based on 73 cases, the relative risk of colorectal cancer associated with a family history of this cancer was 1.72 (95\% CI 1.33-2.20). In our series, based on 70 cases, the corresponding risk was 4.8 (95\% CI 3.7-6.1). For endometrial cancer, a comparison can be made with the CASH study, the largest case-control study of familial factors in endometrial cancer, which included 455 cases of endometrial cancer diagnosed under the age of 55 and 3216 controls. ${ }^{15}$ The authors found that endometrial cancer in a first degree female relative increased the risk of endometrial cancer by 2.8 (95\% CI 1.9-4.2). In comparison, our results (based on 164 first degree female relatives of 36 women diagnosed with endometrial cancer under the age of 55) indicated an increase in relative risk of 11.6 (95\% CI 6.1-19.8). Hence, our data suggest that the risk of either colorectal or endometrial cancer in relatives of probands with double primaries is greater than that associated with either site alone.

The risks are less dramatic for relatives of women in whom both colorectal and endometrial cancer occurred over the age of 55 , as seen in table 3B. This finding indicates that probands having both cancers at an older age are much less likely to have an inherited predisposition to cancer.

Our data are consistent with the finding that this predisposition is specific for HNPCC associated cancers. In our study, there was a significantly increased risk for cancers of the colorectum, endometrium, and pancreas. The risk for cancers of the oesophagus, stomach, small intestine, bladder, and ovary were increased but only ovarian cancer in relatives under the age of 55 reached statistical significance. This finding may be because of the rarity of these cancers and the small numbers seen in our study. The finding of a significantly increased risk for ovarian cancer has previously been reported by Watson and Lynch. ${ }^{16}$

When adjusting for multiple comparisons through the Bonferroni method (using 20 as the number of comparisons), cancers of the colorectum, endometrium, and pancreas remained significant (however ovarian cancer did not). These results suggest that the inherited susceptibility to cancer in these families may be the result of the genetic defect causing HNPCC.

Our observation that the reporting of cancer diagnoses in first degree relatives is very likely to be accurate is consistent with previous reports. ${ }^{1011}$ Eighty percent of the cancers with pathological confirmation were accurately reported. In $20 \%$ of cases, the site of cancer was either different from that originally reported or additional cancers were documented. As noted in table 1 , verification of cancer in several cases showed a second primary cancer, with the first cancer being reported accurately. Additionally, there were many cases where the site of cancer was altered to an HNPCC associated site, pri- 


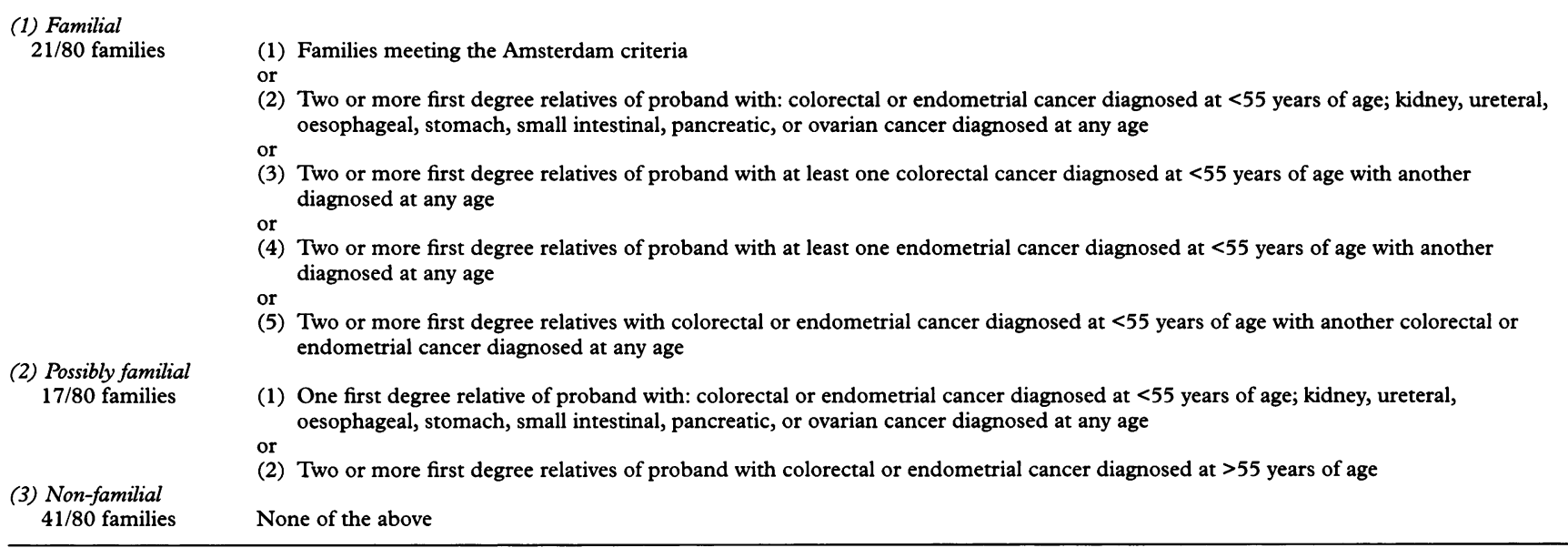

marily the colorectum, endometrium, and pancreas. Our findings suggest that verification of cancer diagnoses increased the significance of our data. Because of possible misclassifications that were undetected, the relative risks reported in our study are likely to be an underestimate.

Pancreatic cancer is a feature of cancer susceptibility syndromes associated with germline mutations in p16, BRCA1, BRCA2, and APC. ${ }^{17}$ Although it has been suggested that pancreatic cancer is in the spectrum of HNPCC associated cancers, the risks reported in previous studies have either been descriptive $e^{3481819}$ or have not reached statistical significance. ${ }^{16}{ }^{20}$ Several studies investigating the tumour spectrum in HNPCC have not mentioned pancreatic cancer. ${ }^{51}$ The substantial increase in relative risk for pancreatic cancer seen in our study was unexpectedly high in comparison to previous reports. Eight cases of pancreatic cancer were seen in seven families; five of the pedigrees were classified as "familial" according to our definitions presented in table 4 . Two of the pedigrees were classified as non-familial based on our criteria.

It is plausible that pancreatic cancer is more common in HNPCC than previously reported. Alternatively, the association may be restricted to studying a subgroup of hereditary colon cancer families. The requirement of a diagnosis of endometrial cancer as well as colorectal cancer in a single proband may have resulted in the selection for families in which extracolonic cancers were more common. The presence of other genetic or environmental factors may account for the high risk for pancreatic cancer seen in our families.

The absence or presence of extracolonic tumours has been used to subdivide HNPCC into Lynch syndromes I and II, respectively. In support of this distinction, Vasen $e t a l^{\beta}$ studied the tumour spectrum in 24 HNPCC kindreds from The Netherlands. In four families, colorectal cancer was the only type of cancer to occur. Sixty-five extracolonic tumours were observed among members of the remaining 20 kindreds. Mutation studies to date, most of which focus on Lynch II kindreds fulfilling the Amsterdam criteria, have failed to show a precise relationship between the clinical pheno- type and the gene involved or the site or type of mutation. Vasen $e t a l^{1}$ reported a higher rate of extracolonic cancer in MSH2 mutation carriers as compared to MLH1 mutation carriers ( $61 \% v 42 \%)$, but the difference was not statistically significant. Phenotypic diversity seen in families with the same genetic predisposition suggests the existence of other genetic or environmental factors. Kindreds sharing an identical predisposing MMR gene mutation provide the opportunity to study the possible role of modifying factors in HNPCC.

There was no increase in the relative risk for lung or breast cancer; neither tumour is believed to be associated with HNPCC. We observed a decreased risk for lung cancer; this finding has been previously reported in studies of extracolonic cancers in HNPCC. Watson and Lynch $^{16}$ found significantly fewer lung/ bronchial cancer cases than expected (relative risk of 0.4 with a $p$ value of $<0.05$ ) in their study of extracolonic cancers in HNPCC. A report of cancer in relatives of patients with colorectal cancer showed that lung cancer occurred only $60 \%$ as often in relatives of patients compared with control subjects. ${ }^{20}$ The same low incidence of cancer compared to the general population was reported by Fitzgibbons et al. ${ }^{22}$ Mecklin et al reported lung cancer in only four of 196 cancer affected family members of 22 families with HNPCC. Conversely, several population based studies have shown significant ${ }^{23} 24$ and non-significant ${ }^{25} 26$ deficits of second cancers of the colorectum after lung cancer. Recently, Wu et $a l^{7}$ reported a deficit of digestive tract cancers in the first degree relatives of non-smoking female lung cancer patients. Foulkes et $a l^{28}{ }^{29}$ reported a deficit of colorectal cancer in the first degree relatives of patients with squamous cell cancer of the head and neck in two separate case-control studies. It appears that an inverse relationship may exist between colorectal cancer and both squamous cell cancer of the head and neck and lung cancer. This phenomenon requires further study of genetic and environmental factors to determine its aetiological basis.

The underlying molecular defect in HNPCC is a defect in DNA repair resulting in a susceptibility to tumorigenesis. Five mismatch repair 
(MMR) genes have been identified (hMSH2, hMLH1, hPMS1, hPMS2, and hMSH6) and mutations in these genes have been found in HNPCC families. ${ }^{30-36}$ Germline mutations in $\mathrm{hMSH} 2$ and $\mathrm{hMLH} 1$ have been implicated in the majority of HNPCC families. ${ }^{37} 38$

Tumours associated with HNPCC frequently show microsatellite instability (MIN) caused by an inactivation of the MMR system. The MIN phenotype is found in $86 \%$ of HNPCC associated colonic tumours compared with $16 \%$ of sporadic cases. ${ }^{39}$ For endometrial cancer, the MIN phenotype has been described in a significant number of both HNPCC associated (75\%) and sporadic (17\%) cases. ${ }^{40}{ }^{41}$ However, most endometrial cancers that have MIN are not associated with identified HNPCC gene mutations, suggesting that germline or somatic mutations in other MMR genes are responsible for the MIN phenotype in most endometrial cancers. ${ }^{42}$ The MIN phenotype has been reported in tumours of the stomach and pancreas ${ }^{43}$ and, rarely, the ovary. ${ }^{44}$ With the availability of mutation analysis of the MMR genes and determination of the MIN phenotype in tumour samples, it is now possible to determine the presence of HNPCC on a molecular basis rather than having to rely on clinical criteria. It is possible that many of our families fitting the "familial" and "possibly familial" criteria in table 4 have a mutation in one of the HNPCC genes.

This study has shown that first degree relatives of women with double primary cancers of the colorectum and endometrium are at a greatly increased risk of colorectal, endometrial, and a variety of other HNPCC related cancers. In fact, of all the known risk factors for colorectal cancer, genetic susceptibility confers the highest risk. Of the genetic factors, the presence of a double primary cancer of the colorectum and endometrium is an important determinant. Based on the results, it is important for treating physicians to ask about past history of cancer, familiy history of cancer, and offer HNPCC genetic testing to any woman with double primary cancers at these sites, particularly if one or both cancers are diagnosed at less than 55 years of age. Appropriate counselling and screening should be offered to first degree relatives.

We thank the probands and their families for cooperation, the many doctors who agreed to contact their patients, Cancer Care Ontario for identifying eligible patients through the registry, and Deborah Lambert for earlier help with statistical analysis. This study was funded in part by a Quebec Cancer Family Network grant from the Fonds de la Recherche en Sante du Quebec (FRSQ).

1 Lynch HT, Lanspa S, Smyrk T, et al. Hereditary nonpolyposis colorectal cancer (Lynch syndromes I \& II). Genetics, pathology, natural history, and cancer control, part I. Cancer Genet Cytogenet 1991;53:143-60.

2 Watson P, Lynch HT. Extracolonic cancer in hereditary nonpolyposis colorectal cancer. Cancer 1993;71:677-85.

3 Aarnio M, Mecklin JP, Aaltonen L, et al. Lifetime risk of different cancers in hereditary nonpolyposis colorectal cancer (HNPCC) syndrome. Int $\mathcal{F}$ Cancer 1995;64:430-3.

4 Dunlop MG, Farrington SM, Carothers AD, et al. Cancer risk associated with germline DNA mismatch repair gene mutations. Hum Mol Genet 1997;6:105-11.
5 Mecklin JP, Jarvinen HJ, Peltokallio P. Cancer family syndrome. Genetic analysis of 22 Finnish kindreds. Gastroenterology 1986;90:328-33.

6 Lynch HT, Lanspa SJ, Boman BM, et al. Hereditary nonpolyposis colorectal cancer - Lynch syndromes I and II. Gastroenterol Clin North Am 1988;17:679-712.

7 Lynch HT, Ens J, Lynch JF, et al. Tumor variation in three extended Lynch syndrome II kindreds. Am $\mathcal{F}$ Gastroenterol 1988;83:741-7.

8 Vasen HF, Offerhaus GJ, den Hartog Jager FC, et al. The tumor spectrum in hereditary nonpolyposis colorectal cancer: a study of 24 kindreds in the Netherlands. Int $\mathcal{F}$ Cancer 1990;46:31-4.

9 Hakala T, Mecklin JP, Forss $M$, et al. Endometrial carcinoma in the cancer family syndrome. Cancer 1991;68: 1656-9.

10 Love RR, Evans AM, Josten DM. The accuracy of patient reports of a family history of cancer. $\mathcal{F}$ Chron Dis 1985;38: 289-93.

11 Aitken J, Bain C, Ward $M$, et al. How accurate is self-reported family history of colorectal cancer? $A m \mathcal{F} E p i-$ demiol 1985;141:863-71.

12 Breslow NE, Day NB. The design and analysis of cohort studies. In: Statistical methods in cancer research. Vol II. Lyon: IARC, 1987

13 Shah S, Evans DGR, Blair V, et al. Assessment of relative risk of second primary tumors after ovarian cancer and the usefulness of double primary cases as a source of material for genetic studies with a cancer registry. Cancer 1993;72: 819-27.

14 Fuch CS, Giovannucci EL, Colditz GA, et al. A prospective study of family history and the risk of colorectal cancer. $N$ Engl F Med 1994;331:1669-74.

15 Gruber SB, Thompson WD, and the Cancer and Steroid Hormone Study Group. A population-based study of endometrial cancer and familial risk in younger women. Cancer Epidemiol Biomarkers Prev 1996;5:411-17.

16 Watson P, Lynch HT. Extracolonic cancer in hereditary nonpolyposis colorectal cancer. Cancer 1993;71:677-85.

17 Flanders TY, Foulkes WD. Pancreatic adenocarcinoma: epidemiology and genetics. $\mathcal{F}$ Med Genet 1996;33:889-98.

18 Mecklin JP, Javinen HJ. Tumor spectrum in cancer family syndrome (hereditary nonpolyposis colorectal cancer) Cancer 1991;68:1109-12.

19 Lynch HT, Voorhees GJ, Lanspa SJ, et al. Pancreatic carcinoma and hereditary nonpolyposis colorectal cancer: a family study. $B r f$ Cancer $1985 ; 52: 271-3$.

20 Ponz de Leon M, Sassatelli R, Sacchetti C, et al. Familial aggregation of tumors in the three-year experience of population-based colorectal cancer registry. Cancer Res 1989;49:4344-8.

21 Vasen HF, Wijnen JT, Menko FH, et al. Cancer risk in families with hereditary nonpolyposis colorectal cancer diagnosed by mutation analysis. Gastroenterology 1996;110. 1020-7.

22 Fitzgibbons RJ, Lynch HT, Slainislav GV, et al. Recognition and treatment of patients with hereditary non-nolyposis colon cancer. Ann Surg 1987;206:289-94.

23 Teppo L, Pukkala E, Saxen E. Multiple cancer - an epidemiologic exercise in Finland. F Natl Cancer Inst 1985; 75:207-17.

24 Lynge E, Jensen OM, Cartensen B. Second cancer following cancer of the digestive system in Denmark 1935-1982. In Greenwald P, ed. Multiple primary cancers in Connecticut and Denmark. NCI monograph No 68. Washington, DC: US GPO, 1985:277-301.

25 Enblad P, Adami HO, Glimelius B, et al. The risk of subsequent primary malignant diseases after cancers of the colon and rectum. A nationwide cohort study. Cancer 1990;65: 2091-100.

26 Hoxr SK, Wilson J, Blot WJ, et al. Second cancer following cancer of the digestive system in Connecticut 1935-1982. In: Greenwald P, ed. Multiple primary cancers in Connecticut and Denmark. NCI monograph No 68. Washington, DC US GPO, 1985:49-82.

27 Wu AH, Fontham ETH, Reynolds P, et al. Family history of cancer and risk of lung cancer among lifetime nonsmoking women in the United States. Am F Epidemiol 1996;143:53542

28 Foulkes WD, Brunet JS, Kowalski LP, et al. Family history of cancer is a risk factor for squamous cell carcinoma of the head and neck in Brazil: a case-control study. Int 7 Cancer 1995;63:769-73.

29 Foulkes WD, Brunet JS, Sieh W, et al. Familial risks of squamous cell carcinoma of the head and neck: retrospective case-control study, $B M F 1996 ; 313: 716-21$.

30 Fishel R, Lescoe MK, Rao MR, et al. The human mutator gene homolog MSH2 and its association with hereditary nonpolyposis colorectal cancer (published erratum in Cell 1994;77:167). Cell 1993;75:1027-38.

31 Leach FS, Nicolaides NC, Papadopoulos N, et al. Mutations of a mutS homolog in hereditary nonpolyposis colorectal cancer. Cell 1993;75:1215-25.

32 Bronner CE, Baker SM, Morrison PT, et al. Mutation in the DNA mismatch repair gene homologue hMLH1 is associated with hereditary nonpolyposis colorectal cancer. Nature 1994;368:258-61. 
33 Papadopoulos N, Nicolaides NC, Wei YF, et al. Mutation of a mut $L$ homolog in hereditary colon cancer. Science 1994; 263:1625-9.

34 Nicolaides NC, Papadopoulos N, Liu B, et al. Mutations of two PMS homologues in hereditary nonpolyposis colorectwo cancer. Nature 1994;371:75-80.

35 Akiyama Y, Sato H, Yamada $T$, et al. Germline mutation of the hMSH6/GTBP gene in an atypical hereditary nonpolyposis colorectal cancer kindred. Cancer Res 1997;57:3920-3.

36 Miyaki M, Konishi M, Tanaka K, et al. Germline mutation of MSH6 as the cause of hereditary nonpolyposis colorectal cancer. Nat Genet 1997;17:271-2

37 Sandkuijl L, Bishop T. Results of the joint analysis of the EUROFAP linkage data: summary. Copenhagen: EUROFAP, 1993.

38 Liu B, Parsons RE, Hamilton SR, et al. hMSH2 mutations in hereditary nonpolyposis colorectal cancer kindreds. Cancer Res 1994;54:4590-4.

39 Aaltonen LA, Peltomaki P, Mecklin JP, et al. Replication errors in benign and malignant tumors from hereditary nonpolyposis colorectal cancer patients. Cancer Res 1994; 54:1645-8.

40 Risinger JI, Berchuck A, Kohler MF, et al. Genetic instability of microsatellites in endometrial carcinoma. Cancer Res 1993;53:5100-3.

41 Kobayashi K, Sagae S, Kudo R, et al. Microsatellite instability in endometrial carcinomas: frequent replication errorsin tumors of early onset and/or of poorly differentiated type Genes Chrom Cancer 1995;14:128-32.

42 Kowalski LD, Mutch DG, Herzog TJ, et al. Mutational analysis of MLH1 and MSH2 in 25 prospectively-acquired RER+ endometrial cancers. Genes Chrom Cancer 1997;18: 219-27.

43 Han HJ, Yanagisawa A, Kato Y, et al. Genetic instability in pancreatic cancer and poorly differentiated type of gastric cancer. Cancer Res 1993;53:5087-9.

44 Fujita M, Enomoto T, Yoshino K, et al. Microsatellite instability and alterations in the $\mathrm{hMSH} 2$ gene in human ovarian cancer. Int $\mathcal{F}$ Cancer 1995;64:361-6. 